\title{
EL DERECHO DE PETICIÓN COMO FACTOR DE DESCONGESTIÓN JUDICIAL EN EL MUNICIPIO DE SINCELEJO - ANÁLISIS DESDE LA PRÁCTICA DEL CONSULTORIO JURÍDICO DE CECAR, DURANTE LOS AÑOS 2016 Y 2017
}

Gunkel Romero Gutiérrez ${ }^{1}$

Edgardo Tadeo Lorduy Viloria ${ }^{2}$

\section{Resumen}

El presente capítulo de libro pretendió establecer la incidencia y efectividad del derecho de petición en la descongestión judicial en el municipio de Sincelejo durante los años 2016 y 2017, teniendo su base en el análisis desde la práctica de Consultorio Jurídico de CECAR. Con dicho capítulo, se buscó a través del estudio histórico, normativo y jurisprudencial en Colombia del derecho de petición, así como el análisis de las estadísticas de derecho público de los documentos elaborados en la práctica del consultorio jurídico de CECAR, establecer la efectividad del derecho de petición en la descongestión de los despachos judiciales de Sincelejo, así como su incidencia en el acceso a la justicia, lográndose analizar que el que el derecho de petición es el medio más utilizado para acudir de manera directa a la reclamación de los derechos del usuario o a la solución del problema planteado con un $68 \%$, frente a su segundo competidor que fue la acción de tutela con un 21\%.

Palabras clave: derecho de petición, descongestión judicial, consultorio jurídico y protección Especial

$1 \quad$ Maestrante en Derecho Administrativo. Especialista en Derecho Administrativo de la Corporación Universitaria del Caribe CECAR, Abogado y Conciliador. Coordinador de Consultorio Jurídico de CECAR con email: Edgardo.lorduy@cecar.edu.co

2 Maestrante en Gestión Pública de la Universidad Nacional de Rosario Argentina. Especialista en Derecho Administrativo de la Corporación Universitaria del Caribe CECAR. Abogado y Conciliador. Email: Gunkel.romero@cecar.edu.co. 


\section{Abstract}

This chapter of the book attempted to establish the incidence and effectiveness of the right of petition in the judicial decongestion in the municipality of Sincelejo during the years 2016 and 2017, having its base in the analysis from the practice of CECAR's Legal Clinic. With this chapter, we searched through the historical, normative and jurisprudential study in Colombia of the right of petition, as well as the analysis of public law statistics of the documents elaborated in the practice of CECAR's legal practice, to establish the effectiveness of the right of petition in the decongestion of Sincelejo's judicial offices, as well as its incidence in the access to justice, being able to analyze that the right of petition is the most used means to go directly to the claim of the rights of the user or to the solution of the problem raised with $68 \%$, compared to its second competitor that was the action of protection with $21 \%$

Keywords: right of petition, judicial decongestion, legal clinic and special protection

\section{Introducción}

En la actualidad es bien sabido que como consecuencia de la notable congestión judicial del país, se ha venido dificultando el acceso a la justicia de varias personas que ven truncado pretensiones y que por ello padecen de la falta de reconocimiento y respeto de sus derechos, debido a la carga que tiene la rama judicial con el represamiento de procesos judiciales con ocasión a las deficiencias y problemáticas que presenta, lo que conlleva a que desde los consultorios jurídicos de las universidades se contribuya a la descongestión y a la misma vez al acceso de justicias de los usuarios que acuden a ellos en ayuda. En el presente capitulo presentamos el derecho a pedir que tienen todas las personas de exigir algo de alguien de manera respetuosa, pues pedir es un derecho inherente al ser humano desde sus principios evolutivos hasta la actualidad el cual con ocasión a su necesidad de uso para las personas ha sido plasmado a través del tiempo en las constituciones y leyes que nos rigen, por lo que se ha elevado dicho derecho a rango de derecho fundamental, además de ostentar la calidad de mecanismo de participación ciudadana y hasta se podría considerar como una herramienta para la solución alterna de los conflictos, lo que le permite a todas las personas tener acceso directo a la justicia y evita con ello el desgaste judicial en una posterior acción de tutela, demanda laboral o de 
El derecho de petición como factor de descongestión judicial en el municipio de Sincelejo - análisis desde la práctica del Consultorio Jurídico de CECAR...

nulidad y restablecimiento del derecho, lo que evitaría que muchos casos no llegasen a congestionar los despachos judiciales.

Es por lo anterior se hace necesario preguntarnos ¿Cuál es la incidencia del derecho de petición en la descongestión judicial en el distrito judicial de Sincelejo desde la práctica del consultorio jurídico de CECAR durante los años 2016 y 2017 ? Es claro que para resolver el anterior interrogante debemos en primera medida establecer la incidencia del derecho de petición en la descongestión judicial del distrito judicial de Sincelejo durante los años 2016 y 2017, así mismo como punto segundo debemos conceptualizar el derecho de petición en el marco histórico, normativo, y jurisprudencial en Colombia para así poder tener claridad de la regulación de este derecho en nuestro contexto nacional y en los diferentes ramos en que se encuentra regulando.

Otro punto que es indispensable es la efectividad del derecho de petición judicial en el distrito judicial del municipio de Sincelejo, pues es bien sabido que este se encuentra al igual que muchos despachos judiciales del país con cierta congestión producto de los múltiples conflictos jurídicos que no son solucionados de manera previa cuando se acude de manera directa a la contraparte por la vía de la petición, pues muchos de los que reciben las peticiones respetuosas se enfrascan en negativas en reconocer y otorgar los que se pide solo por el simple hecho de dilatar el derecho que le asiste al peticionario y con ello no dar soluciones positivas que evitarían la puesta en marcha del sistema judicial para reclamar un derecho que se niega a sabiendas de que lo que se solicitando es procedente y que por ende quien tiene la razón o le asiste el derecho quien está pidiendo.

Es indispensable además relacionar las estadísticas del Consultorio Jurídico sobre el derecho de petición durante los años antes mencionados, estimando en sí, el impacto de la práctica jurídica del Consultorio Jurídico de CECAR en la descongestión de los despachos judiciales del municipio de Sincelejo en aras establecer el impacto de nuestro trabajo en dichos despachos. Es importante desarrollar la temática descrita en el presente capítulo, por cuanto el derecho a pedir de las personas es un derecho fundamental y que a su vez es un mecanismo de participación de la ciudadanía que le permite pedir respetuosamente a las entidades públicas o privadas la resolución de conflictos o de situaciones particulares o colectivas, las cuales pueden ser atendidas y solucionadas por este medio, y que evitan muchas veces que lleguen a las instancias prejudiciales y judiciales. 
Para todo lo anterior utilizaremos las estadísticas de los años 2016 y 2017 las cuales nos permitirán poder tener información real y pertinente sobre los casos que se utilicen para sustentar la presente investigación.

\section{El derecho de petición en el marco histórico, normativo y jurispruden- cial en Colombia}

El derecho a pedir es la facultad que tiene cada persona de exigir algo de alguien, bien sea para que a quien se lo dirigen haga algo o para que no, con la expectativa de que recibirá una pronta solución a la petición impetrada. En palabras del doctor Bartomeu Colom Pastor el derecho de petición: “... Es el derecho de los ciudadanos de dirigir peticiones a los poderes públicos que señalen las leyes, sobre las materias de su competencia, cuando no son titulares de derechos subjetivos o de intereses legítimos". Complementa lo anterior indicando que "En efecto, si el ciudadano es titular del derecho subjetivo o de un interés un legítimo, lo que debe dirigir a la administración es una solicitud de iniciación de un procedimiento o ejercitar el derecho de acción ante los tribunales" (Bartomeu, 1997)

En la actualidad es bien recibida y acogida la anterior definición del derecho de petición agregándole eso sí, que además de las autoridades públicas también se aplica a las entidades privadas e inclusive va más allá, puesto que bajo ciertos preceptos opera frente a personas naturales particulares. El derecho de petición es un derecho fundamental de toda persona, pues se consagra dentro del Título II Capítulo I, artículo 23 de la Constitución Política, es por ello que este derecho sea susceptible de protección especial mediante la acción de tutela, pues por su naturaleza, la petición es de aplicación inmediata de la cual se debe emitir respuesta dentro del término legalmente establecido, con claridad en su manifestación y con argumentos de fondo, es decir que la respuesta dada este acorde con lo pedido.

Como preceptos para destacar en la petición tenemos las siguientes características que son de suma importancia, ya que están acorde a nuestro Estado Social de Derecho y plasma sus principales postulados, estas son: elevar la Petición a Derecho fundamental, autorizar la petición para cual quiera persona, incluyendo a menores de edad y extranjeros, para la presentación de la petición no se exige ser abogado, la obligatoriedad de dar respuesta por parte de las autoridades, permitir que se puedan interponer a particulares, los medios de impugnación o recursos que garantizan el principio de contradicción, en caso de no estar de acuerdo con la respuesta, en caso de no sé de respuesta a la 
El derecho de petición como factor de descongestión judicial en el municipio de Sincelejo - análisis desde la práctica del Consultorio Jurídico de CECAR...

petición poderla exigir vía tutela. Así destacamos los puntos relevantes de la petición donde demostramos los postulados esenciales del Estado Social de Derecho.

Adicional a las anteriores características, es menester resaltar la naturaleza gratuita del derecho de petición, pues por ser un derecho fundamental y de participación su ejercicio no puede ser objeto de cobro alguno por parte de las entidades que son objeto de ellas, es más, ni siquiera la respuesta que es enviada por correo desde cualquier municipio del país a otro, puede ser óbice para exigir al peticionario que devuelva el valor del envío o que para que le llegue la respuesta deba pagarlo, lo que demuestra claramente la relevancia, importancia y trascendencia de este magno derecho en nuestro país, y que muy seguramente es de darse así en casi todos los países democráticos donde se respeten los derechos inherentes al ser humano como lo es la petición; claro está que lo que si puede hacer las entidades peticionarias en las que son peticiones de entrega de documentos, es exigir el pago del número de copias del documento o documentos que desea recibir o que solicito mediante su petición de entrega de copia de documentos.

En Colombia es claro traer a colación que según la Ley 1437 de 2011:

La normatividad aplicable en la actualidad para garantizar el derecho de petición está conformada por las siguientes disposiciones: (i) la Constitución Política, en especial sus artículos 23 y 74; (ii) los tratados internacionales suscritos y ratificados por Colombia que regulan el derecho de petición, entre otros derechos humanos; (iii) los principios y las normas generales sobre el procedimiento administrativo, de la Parte Primera, Título I del Código de Procedimiento Administrativo y de lo Contencioso Administrativo (Ley 1437 de 2011), así como las demás normas vigentes de dicho código que se refieren al derecho de petición o que, de una u otra forma, conciernen al ejercicio del mismo (notificaciones, comunicaciones, recursos, silencio administrativo etc.); (iv) las normas especiales contenidas en otras leyes que regulan aspectos específicos del derecho de petición o que se refieren a éste para ciertos fines y materias particulares; (v) la jurisprudencia vigente, especialmente aquélla proveniente de la Corte Constitucional y del Consejo de Estado (Ley 1437, 2011) 
Pero, que para este capítulo del libro trataremos la norma principal y relacionaremos de manera breve varias de las regulaciones especiales y específicas que se encuentran en nuestro ordenamiento jurídico que establecen procedimientos para el trámite de las peticiones en cada una de las materias y entidades donde han sido creados.

\section{Historia del Derecho de Petición en las Constituciones Políticas de Colombia}

Pedir es un arte, mediante el cual quien lo domina puede acceder a infinitas posibilidades sin tener que acudir a instancias posteriores para obtener lo que quiere, lo que necesita o lo que por justa razón le corresponde. Es así como el derecho a pedir se encuentra inmerso a nuestro criterio en cada una de las particularidades del derecho y de las relaciones humanas mismas, pues es un derecho natural de las personas que sin duda alguna permea todo el sistema jurídico y que emana de la naturalidad humana en cada uno de sus contextos. Las relaciones interpersonales se rigen por reglas básicas establecidas como consecuencia de la interacción histórica entre los seres humanos desde sus principios evolutivos.

Así las cosas, el ordenamiento jurídico colombiano, no es ajeno a las realidades de las personas que conforman este país, pues desde los inicios de la Republica de Colombia, se instauro en las diferentes constituciones el particular derecho, es así que haremos un breve repaso histórico comenzando con la Constitución de 1821 (Constitución de Nueva Granada), pasando por las constituciones de 1863 (Constitución de los Estado Unidos de Colombia), por la constitución de 1886 (Constitución de Política de Colombia) hasta la Constitución actual, la cual fue creada mediante constituyente del 04 de julio de 1991.

La Constitución de 1821 nacida el 30 de agosto en su Título VIII correspondiente a disposiciones generales fue la primera de las constituciones en establecer clara e inequívocamente la posibilidad a los ciudadanos de reclamar ante las autoridades públicas de la época el respeto de sus derechos situación que plasmo en su artículo 157:

La libertad que tienen los ciudadanos de reclamar sus derechos ante los depositarios de la autoridad pública, con la moderación y respeto debidos, en ningún tiempo será impedida ni limitada. Todos, por el contrario, deberán hallar un remedio pronto y seguro, con arreglo a las leyes, (...)". (Constitución, 1821) 
El derecho de petición como factor de descongestión judicial en el municipio de Sincelejo - análisis desde la práctica del Consultorio Jurídico de CECAR...

Por su parte la Constitución Política de Los Estados Unidos de Colombia o Constitución de 1863 firmada por los estados de Antioquia, Bolívar, Boyacá, Cauca, Cundinamarca, Magdalena, Panamá, Santander y Tolima el día 08 de mayo de 1863 demarca nuevamente la necesidad de darle a todos los ciudadanos "El derecho de obtener pronta resolución en las peticiones que por escrito dirijan a las corporaciones, autoridades $o$ funcionarios públicos, sobre cualquier asunto de interés general o particular" (Constitución Política de los Estado Unidos de Colombia, 1863) lo que los faculta para acceder a la administración mediante la petición, permitiéndose de esta manera tener una oportunidad y una herramienta practica de exigir sus derechos.

La penúltima Constitución, la de 1886 en el título III, articulo 45 exclamo el derecho legítimo de toda persona a pedir de manera respetuosa ante las autoridades de ese entonces, con la finalidad de darle acceso a sus ciudadanos de poder participar más activamente en las reclamaciones que tuviesen frente a la administración, dicha situación obedece al sometimiento que tuvieron de la corona española y que por tanto les impidió durante mucho tiempo ejercer los derechos y garantías civiles que con esta constitución se plasmaron con mucha mayor claridad, es por ello que el artículo 45 estableció que "Toda persona tiene derecho de presentar peticiones respetuosas a las autoridades, ya sea por motivos de interés general, ya de interés particular, y el de obtener pronta resolución". (Constitución Politica de la República de Colombia, 1886), este es el penúltimo paso hacia la consolidación del derecho a pedir en nuestro país, pues recordemos que Colombia mediante constituyente de fecha 04 de julio de 1991 creo la Constitución Política de Colombia de 1991 y que es la que se encuentra vigente actualmente y plasma en nuestro ordenamiento jurídico el derecho a cada una de las personas de pedir bajo la condición simple de que esta sea respetuosa, la obligación de dar pronta respuesta y la orden al mismo Estado de reglamentar el mismo.

\section{Actualidad de la normatividad principal del derecho de Petición en Colombia}

El artículo 23 y el artículo 74 de la Constitución Política de Colombia (Constitución Politíca de Colombia, 1991) son la punta de lanza en nuestro ordenamiento jurídico en materia de derecho de petición, pues en ella se establece como un derecho fundamental de todas las personas naturales y jurídicas, públicas o privadas de presentar peticiones respetuosas ante 
cualquier autoridad pública bien sea en interés particular o en interés general con la obligación para el que la recibe de dar una pronta solución a lo pedido de forma clara, concisa y de fondo. En cumplimiento del artículo antes enunciado por vía legal es decir por medio de la ley 1437 de 2011, en su título I, capitulo II, establece en su artículo 4 a la petición como dos formas de iniciar las actuaciones administrativas ante los entes estatales de la siguiente forma i), Por quienes ejerciten el derecho de petición, en interés general y ii). Por quienes ejerciten el derecho de petición, en interés particular"; mediante las cuales se da inicio a las actuaciones administrativas que busca poner en conocimiento de la administración una situación particular o general y recibir de dicha administración una respuesta clara, oportuna y de fondo y dependiendo de dicha respuesta seguir con el tramite pertinente para la consecución del derecho reclamado.

Así mismo el articulo 13 reitera que "Toda persona tiene derecho a presentar peticiones respetuosas a las autoridades, en los términos señalados en este código, por motivos de interés general o particular, y a obtener pronta resolución completa y de fondo sobre la misma", entiéndase en interés general aquellas peticiones que buscan un bien colectivo común que va a beneficiar a un número indeterminado de personas con la presentación de esta clase de petición, mientras que la de interés particular se busca la solución de un problema o el reconocimiento de un derecho particular para un caso concreto e individual de quien la presenta. A su vez en el artículo 5 numeral $1^{\circ}$ estipula las modalidades en que pueden presentarse las peticiones, por lo que menciona tres modos de presentarlas, "verbalmente, o por escrito, o por cualquier otro medio idóneo".

La primera es la presentada de manera verbal, es decir el articulo permite que las personas puedan presentarse ante la entidad objeto de petición y por medio del habla pedir lo que requiere y que por haberla presentado de esa forma, el funcionario no puede negarse a recibirla, y además de eso "deberá quedar constancia de la misma", según lo contempla el Artículo 15, inciso $1^{\circ}$ ley 1437 de 2011, modificado por el artículo $1^{\circ}$ de la (Ley 1755,2015$)$. Es menester hacer saber que lo manifestado en el párrafo anterior es la regla general en cuanto a las peticiones verbales, pero que puede darse en condiciones legales establecidas una excepción, pues el artículo 15 inciso $4^{\circ}$ de la misma ley establece una especie de ventana para la posibilidad de que "Las autoridades podrán exigir que ciertas peticiones se presenten por escrito, y pondrán a disposición de los interesados, sin costo, a menos que una ley expresamente señale lo 
El derecho de petición como factor de descongestión judicial en el municipio de Sincelejo - análisis desde la práctica del Consultorio Jurídico de CECAR...

contrario, formularios y otros instrumentos estandarizados para facilitar su diligenciamiento", pero pese a dicha ventana citada, es de resaltar que la misma es relativa y limitada, ya que ese mismo artículo más adelante establece que:

En todo caso, los peticionarios no quedarán impedidos para aportar o formular con su petición argumentos, pruebas o documentos adicionales que los formularios no contemplen, sin que por su utilización las autoridades queden relevadas del deber de resolver sobre todos los aspectos y pruebas que les sean planteados o presentados más allá del contenido de dichos formularios.

La segunda forma de presentar las peticiones ante las entidades, es la más comúnmente utilizada y estipulada en el artículo mismo que corresponde a las presentadas de forma escrita y que deben ser entregadas personalmente o por interpuesta persona ante la entidad a la cual es dirigida, o también puede enviar el escrito de petición por correo a la entidad de destino y por ese simple hecho no se hace merecedor a que su petición no sea tenida en cuenta. Al igual que con la petición verbal, el artículo 15 inciso $5^{\circ}$ de la misma ley, nos narra que a la petición escrita se podrá acompañar una copia que, recibida por el funcionario respectivo con anotación de la fecha y hora de su presentación, y del número y clase de los documentos anexos, tendrá el mismo valor legal del original y se devolverá al interesado a través de cualquier medio idóneo para la comunicación o transferencia de datos. Esta autenticación no causará costo alguno al peticionario, con lo que se establece el breve procedimiento para recibir la petición escrita por parte de la entidad que la recibe y ante quien está dirigida.

La tercera y última forma estipulada en el artículo $5^{\circ}$ numeral $1^{\circ}$ de la ley 1437 de 2011, obedece y tiene su razón de ser principalmente con ocasión al sin número de avances tecnológicos de nuestra era que han influenciado la ley en comento hasta tal punto que se crea una puerta bastante grande para las múltiples posibilidades que se están presentando y que se puedan presentar en un futuro a corto, mediano y a largo plazo, pues se estipula claramente la opción al peticionario de acudir a esas tecnologías para presentar sus peticiones "por cualquier otro medio idóneo", lo que evidencia la trascendencia del derecho de petición en el tiempo, por lo que se estipula el cómo se debe tramitar dado el caso se utilicen medios de trasferencia de datos en el parágrafo $1^{\circ}$ del artículo mencionado que reza "En caso de que la petición sea enviada a través de 
cualquier medio idóneo para la comunicación o transferencia de datos, esta tendrá como datos de fecha y hora de radicación, así como el número y clase de documentos recibidos, los registrados en el medio por el cual se han recibido los documentos", es decir que usted en algún momento cercano, pues en muchos casos ya está sucediendo, podrá presentar sus peticiones por medio de los email, por medio de las páginas web, por medio de las redes sociales y porque no, por medio de aplicaciones como whatsapp y similares, sin que eso signifique de que se tengan como no presentadas ante la entidad que las recibe, eso sí para que se puedan validar esas peticiones, las entidades que las reciben deben tener habilitada esas plataformas para esos fines.

Por su parte el Título II, Capítulo I donde se fijan las reglas generales de la petición y se regula el procedimiento general de la ley 1437 de 2011 , en su artículo $14^{\circ}$ nos fija los términos dentro de los cuales las entidades objeto de petición deben dar respuesta desde el día siguiente en que han recibido la petición, siendo la regla general para todas las peticiones que "Toda petición deberá resolverse dentro de los quince (15) días siguientes a su recepción”, pero que pese a ello en el derecho es bien sabido que toda regla general tiene su excepción y en materia de derecho de petición no le es ajena esa regla, pues se plasmó dos claras excepciones que son a las peticiones de documentos y de información es de diez (10) días, mientras que cuando se trate de peticiones de Consulta de temas a su cargo el termino será mucho más amplio y se le concede uno de treinta (30) días, los anteriores términos sin perjuicio que puedan ser ampliados hasta el doble del tiempo inicial fijado por la ley, eso sí bajo la condición de que dicha situación sea informada al usuario dentro del término y antes de su vencimiento dándole a este un lapso de tiempo razonable para responderle, sin exceder como ya se dijo del doble del tiempo inicial.

Adicional a las dos excepciones planteadas existe una más que no tiene termino fijo para responder, sino que está sujeta a la condición especial presentada en la petición y soportada con prueba sumaria por lo menos, tal y como nos dice el Artículo 20 de la ley tratada, "Atención prioritaria de peticiones. Las autoridades darán atención prioritaria a las peticiones de reconocimiento de un derecho fundamental cuando deban ser resueltas para evitar un perjuicio irremediable al peticionario, quien deberá probar sumariamente la titularidad del derecho y el riesgo del perjuicio invocado", y continua la norma planteando otras situaciones que son de atención prioritaria y preferente "Cuando por 
El derecho de petición como factor de descongestión judicial en el municipio de Sincelejo - análisis desde la práctica del Consultorio Jurídico de CECAR...

razones de salud o de seguridad personal esté en peligro inminente la vida o la integridad del destinatario de la medida solicitada, la autoridad adoptará de inmediato las medidas de urgencia necesarias para conjurar dicho peligro, sin perjuicio del trámite que deba darse a la petición. Si la petición la realiza un periodista, para el ejercicio de su actividad, se tramitará preferencialmente", lo aquí sentado es el soporte legal y las razones claras del porque las entidades públicas o privadas deben omitir los términos arriba señalados y sujetan la resolución de la petición a unas condiciones muy especiales como cuando la petición va dirigida al reconocimiento de un derecho fundamental para evitar un perjuicio irremediable, por salud, por peligro inminente a la vida, por lo que no podrán argumentarle al peticionario que están dentro del término legal para responderle y que por ello debe esperar los 10, 15 o 30 días.

Para que la petición pueda ser atendida en todo su conjunto y que cuente con la información clara, precisa y con los soportes necesarios para que no sea tenida como incompleta y tener que requerirlo para que la subsane (artículo 17), se estableció por parte de esta ley unos requisitos mínimos que las peticiones de deberán contener, las cuales se fijaron en el artículo 16 de la Ley 1437 de 2011 el cual las enumera así:

1. La designación de la autoridad a la que se dirige: Esto corresponde al nombre de la entidad pública, privada o de la persona natural a quien va a ir dirigida la petición

2. Los nombres y apellidos completos del solicitante y de su representante y o apoderado: si es el caso, con indicación de su documento de identidad y de la dirección donde recibirá correspondencia: Es lo referente a los datos personales de quien va a presentar la petición, pues quien va a recibirla debe saber los datos de la persona que solicita para poder dirigirse a ella claramente en la respuesta que vaya a emitir.

3. El objeto de la petición: Entiéndase este como los temas objeto de solicitudes mediante el derecho de petición, es decir los asuntos por los cuales usted puede reclamar y pedir a quien dirige su petición, los cuales relaciono así, “i). El reconocimiento de un derecho, ii). La intervención de una entidad o funcionario, iii). La resolución de una situación jurídica, iv). La prestación de un servicio, v.) Requerir información, vi). Consultar, vii). Examinar y requerir copias de documentos, viii). Formular consultas, quejas, denuncias y reclamos e interponer recursos." (Artículo 13, inciso segundo de la Ley 14437 de 2011) 
4. Las razones en las que fundamenta su petición: Es lo relacionado con los hechos de la petición con los cuales usted va presentar sus argumentos para fundamentar con ellos su petición, es decir son la narración de las situaciones fácticas colectivas o particulares que motiva al peticionario a acudir al ejercicio del artículo 23 de la Constitución Política de Colombia, los cuales consideramos deben ser enunciados de forma cronológica y enumerada de principio a fin por decirlo así, de forma clara, sin imprecisiones y acorde a lo que se pide.

5. La relación de los documentos que desee presentar para iniciar el trámite: Estos son todos y cada uno de aquellos documentos que sirvan como soporte de los hechos y peticiones y que justifiquen o prueben lo que se está pidiendo.

6. La firma del peticionario cuando fuere el caso: Como es de esperarse la rúbrica de quien está pidiendo es indispensable en los documentos escritos, pues esta avala y confirma que quien pide es la persona titular del derecho reclamado o de la situación por la cual se pide. Es de resaltar que para las peticiones que se presentan por otros medios idóneos dependerá de la forma que se utilice para presentar, enviar o entregar la petición.

La obligación que impone la Constitución y la Ley de atender las peticiones respetuosas dándoles respuesta clara, pronta y oportuna no es exclusiva de las entidades públicas, pues la constitución y la ley las extiende a entidades privadas y adicional a eso la extendió a personas naturales bajo circunstancias especiales, pues así quedo estipulado en los artículos 32 inciso $1^{\circ}$, en su parágrafo $1^{\circ}$ y en el artículo 33 de la referida ley y que el primero establece: "Toda persona podrá ejercer el derecho de petición para garantizar sus derechos fundamentales ante organizaciones privadas con o sin personería jurídica, tales como sociedades, corporaciones, fundaciones, asociaciones, organizaciones religiosas, cooperativas, instituciones financieras o clubes", mientras que el segundo dice: "Sin perjuicio de lo dispuesto en leyes especiales, a las Cajas de Compensación Familiar, a las Instituciones del Sistema de Seguridad Social Integral, a las entidades que conforman el sistema financiero y bursátil y a aquellas empresas que prestan servicios públicos y servicios públicos domiciliarios, que se rijan por el derecho privado, se les aplicarán en sus relaciones con los usuarios, en lo pertinente, las disposiciones sobre derecho de petición previstas en los dos capítulos anteriores" 
El derecho de petición como factor de descongestión judicial en el municipio de Sincelejo - análisis desde la práctica del Consultorio Jurídico de CECAR...

\section{Principales Regulaciones Normativas Especiales del Derecho de Petición en Colombia.}

A continuación, nos permitimos mencionar algunas leyes o decretos especiales que en cumplimiento del artículo 23 de la Constitución Política y en concordancia con la Ley 1437 de 2011, enuncian el derecho que tienen las personas de presentar sus peticiones respetuosas según la materia a su cargo y área de influencia y que también estipulan un trámite especial, complementario o relativamente diferente al establecido en la ley citada, por lo que relaciono las siguientes:

1. Ley 142 de 1994, Por la cual se establece el régimen de los servicios públicos domiciliarios y se dictan otras disposiciones. Título VIII, Capitulo VII, Articulo 152 y 153 Defensa de los usuarios en Sede de la Empresa:

Artículo 152: Derecho de petición y de recurso. Es de la esencia del contrato de servicios públicos que el suscriptor o usuario pueda presentar a la empresa peticiones, quejas y recursos relativos al contrato de servicios públicos. Las normas sobre presentación, trámite y decisión de recursos se interpretarán y aplicarán teniendo en cuenta las costumbres de las empresas comerciales en el trato con su clientela, de modo que, en cuanto la ley no disponga otra cosa, se proceda de acuerdo con tales costumbres.

Artículo 153 De la oficina de peticiones y recursos: Todas las personas prestadoras de servicios públicos domiciliarios constituirán una "Oficina de Peticiones, Quejas y Recursos", la cual tiene la obligación de recibir, atender, tramitar y responder las peticiones o reclamos y recursos verbales o escritos que presenten los usuarios, los suscriptores o los suscriptores potenciales en relación con el servicio o los servicios que presta dicha empresa.

2. Ley 962 de 2005: Por la cual se dictan disposiciones sobre racionalización de trámites y procedimientos administrativos de los organismos y entidades del Estado y de los particulares que ejercen funciones públicas o prestan servicios públicos. Título I, Capítulo I, artículo $6^{\circ}$ inciso 3 Disposiciones comunes a toda la administración pública: "Toda persona podrá presentar 
peticiones, quejas, reclamaciones o recursos, mediante cualquier medio tecnológico o electrónico del cual dispongan las entidades y organismos de la Administración Pública".

3. Ley 1266 de 2008: Ley Hábeas Data Y Manejo De La Información Contenida en Bases De Datos Personales, Por la cual se dictan las disposiciones generales del hábeas data y se regula el manejo de la información contenida en bases de datos personales, en especial la financiera, crediticia, comercial, de servicios y la proveniente de terceros países y se dictan otras disposiciones en su artículo $6^{\circ}$ numeral 1.1, 1.2, 1.3, 1.4, 2.1, 2.2, 2.3, así como también el artículo $7^{\circ}$ numeral $1^{\circ}$.

\section{Preceptos jurisprudenciales relevantes del Derecho de Petición}

El derecho de petición también ha sido debatido ampliamente por la jurisprudencia de nuestra Corte Constitucional, pues desde su implementación en la Constitución de 1991, pues se ha resaltado la importancia y relevancia que tiene para las personas el ejercicio de este derecho por parte de todos, así como su protección con el reconocimiento, respeto y cumplimiento por las entidades públicas de todo orden, posiciones que han quedado sentada en las sentencias de la corporación que ha reiterado dichos postulados en diferentes tiempos desde el funcionamiento de nuestra máxima corte: "La Corte Constitucional se ha referido en distintas oportunidades a la importancia de esta garantía fundamental, cuya efectividad, según se ha reconocido:

Resulta indispensable para el logro de los fines esenciales del Estado, particularmente el servicio de la comunidad, la promoción de la prosperidad general, la garantía de los principios, derechos y deberes consagrados en la Constitución y la participación de todos en las decisiones que los afectan, así como para asegurar que las autoridades cumplan las funciones para las cuales han sido instituidas, de acuerdo al artículo 2o. Constitución Política colombiana (Sentencia T-332, 2015)

Por lo anterior ha Corte realiza una rigurosa cronología del derecho de petición desde la Constitución de 1991 mediante la sentencia T-487 de 2017 que a su vez esta enriquecida por preceptos anteriores y que cita sentando nuevamente unas reglas y criterios de aplicación de la siguiente forma: El derecho de petición fue establecido en el artículo 23 de la Constitución, donde se prevé que "toda persona tiene derecho 
El derecho de petición como factor de descongestión judicial en el municipio de Sincelejo - análisis desde la práctica del Consultorio Jurídico de CECAR...

a presentar peticiones respetuosas a las autoridades por motivos de interés general o particular y a obtener pronta resolución". Durante los primeros años de vigencia de la Constitución de 1991, la norma legal de referencia para el derecho de petición fue el Decreto 01 de 1984 Por el cual se reforma el Código Contencioso Administrativo, que regulaba su ejercicio entre los artículos 5, 6, 7, 8, 31, 32, 33 y 39, principalmente. En dicho escenario la Corte Constitucional identificó los contenidos mínimos de ese derecho fundamental, señalando además el sistema de reglas que rigen su cumplimiento y aplicación, precisando que su contenido esencial comprende los siguientes elementos:

a) la posibilidad cierta y efectiva de elevar, en términos respetuosos, solicitudes ante las autoridades, sin que éstas se nieguen a recibirlas o se abstengan de tramitarlas; b) la respuesta oportuna, es decir, dentro de los términos establecidos en el ordenamiento jurídico; c) la respuesta de fondo o contestación material, lo que supone que la autoridad entre en la materia propia de la solicitud, sobre la base de su competencia, refiriéndose de manera completa a todos los asuntos planteados (plena correspondencia entre la petición y la respuesta), excluyendo fórmulas evasivas o elusivas; y d) la pronta comunicación de lo decidido al peticionario, con independencia de que su sentido sea positivo o negativo.

Conforme lo dispone la jurisprudencia de la Corte Constitucional y lo ha venido reiterando, el ejercicio del derecho de petición en Colombia está regido por las siguientes reglas y elementos de aplicación:

1) El de petición es un derecho fundamental y resulta determinante para la efectividad de los mecanismos de la democracia participativa.

2) Mediante el derecho de petición se garantizan otros derechos constitucionales, como los derechos de acceso a la información, la libertad de expresión y la participación política.

3) La respuesta debe satisfacer cuando menos tres requisitos básicos: (i) debe ser oportuna, es decir, debe ser dada dentro de los términos que establezca la ley; (ii) la respuesta debe resolver de fondo el asunto solicitado. Además de ello, debe ser clara, precisa y congruente con lo solicitado; y (iii) debe ser puesta en conocimiento del peticionario.

4) La respuesta no implica necesariamente la aceptación de lo solicitado, ni se concreta necesariamente en una respuesta escrita. 
5) El derecho de petición fue inicialmente dispuesto para las actuaciones ante las autoridades públicas, pero la Constitución de 1991 lo extendió a las organizaciones privadas y en general, a los particulares.

6) Durante la vigencia del Decreto 01 de 1984 el término para resolver las peticiones formuladas fue el señalado por el artículo 6 del Código Contencioso Administrativo, que señalaba un término de quince (15) días para resolver, y en los casos en que no pudiere darse la respuesta en ese lapso, entonces la autoridad pública debía explicar los motivos de la imposibilidad, señalando además el término en el que sería dada la contestación.

7) La figura del silencio administrativo no libera a la administración de la obligación de resolver oportunamente la petición, pues su objeto es distinto. En sentido concurrente, el silencio administrativo es prueba de la violación del derecho de petición.

8) La falta de competencia de la entidad ante quien se plantea el derecho de petición no la exonera del deber de responder.

9) La presentación de una petición hace surgir en la entidad, la obligación de notificar la respuesta al interesado.

Posteriormente sería expedida la Ley 1437 de 2011 "Por la cual se expide el Código de Procedimiento Administrativo y de lo Contencioso Administrativo", que destinó el Título II de la Primera Parte, artículos 13 a 33, al Derecho de Petición, dividiendo la materia en tres capítulos referidos a las reglas generales del derecho de petición ante autoridades, las reglas especiales del derecho de petición ante autoridades y el derecho de petición ante organizaciones e instituciones privadas, respectivamente. Este título sería declarado inexequible por la Sentencia C-818 de 2011 por violación de la reserva de ley estatutaria, otorgándole al Congreso un plazo de dos años para la expedición de la respectiva ley.

Finalmente fue expedida la Ley 1755 de 2015 "Por medio de la cual se regula el Derecho Fundamental de Petición y se sustituye un título del Código de Procedimiento Administrativo y de lo Contencioso Administrativo", una norma de carácter estatutario, conformada por 33 artículos, sectorizados en tres capítulos, que establecen la regulación integral de ese derecho fundamental, cuyo proyecto fue objeto de control previo de constitucionalidad por medio de la Sentencia C-951 de 2014. ((Sentencia de Tutela T-487, 2018)

Este derecho fundamental tampoco ha sido reprimido por quererse hacer valer antes las entidades privadas y particulares, pues 
El derecho de petición como factor de descongestión judicial en el municipio de Sincelejo - análisis desde la práctica del Consultorio Jurídico de CECAR...

la ley 1437 de 2011 en su artículos 32 y 33, sustituidos por el artículo $1^{\circ}$ de la ley 1755 de 2015 y la corte también aprovecho en la sentencia inmediatamente anterior citada conceptuando al respecto y dando su concepto reiterado de la siguiente forma: El derecho de petición ante particulares, de acuerdo a El Decreto 01 de 1984, que contenía el Código Contencioso Administrativo derogado, no regulaba el ejercicio del derecho de petición ante particulares. Sin embargo la jurisprudencia de la Corte Constitucional dispuso su procedencia, estableciendo un sistema de reglas aplicables en desarrollo de los artículos 2, 20, 23 y 86 de la Constitución Política. Dentro de esta perspectiva la Sentencia SU166 de 1999 había dispuesto en dicho escenario, que la procedencia del derecho de petición ante particulares estaba regida por los siguientes elementos y reglas:

1) La Constitución de 1991 amplió el alcance del derecho fundamental de petición, pues este se predica respecto de la administración y de las organizaciones privadas, precisando que el ámbito de aplicación en estas últimas era limitado.

2) En el ejercicio del derecho de petición ante particulares, deben diferenciarse dos situaciones: (i) si la organización privada presta un servicio público o si por la función que desempeña adquiere el status de autoridad, el derecho de petición opera como si se tratase de una autoridad pública; y (ii) cuando el sujeto pasivo del derecho de petición es una organización que no actúa como autoridad, sólo opera cuando el Legislador lo haya reglamentado. Por lo mismo, la posibilidad de ejercer el amparo de este derecho contra particulares, depende del ámbito y de las condiciones que señale el Legislador.

3) La extensión del derecho de petición a particulares que no actúan como autoridad, sólo es procedente cuando el derecho de petición sea el instrumento para garantizar otros derechos fundamentales, pues su ejercicio no puede implicar una intromisión en el fuero privado de quienes no exponen su actividad al examen público.

Posteriormente la Corte Constitucional haría lugar a la procedencia del derecho de petición ante particulares, en aquellos casos en que exista una relación de subordinación o un estado de indefensión, como desarrollo de lo previsto para el ejercicio de la acción de tutela contra particulares, por el artículo 86 de la Constitución y el artículo 42 del Decreto 2591 de 1991. El tema del derecho de petición ante particulares seguiría desarrollándose. 
Más recientemente y a modo de balance, la Sentencia T-268 de 2013 reiteró la procedencia del derecho de petición ante particulares en seis eventos:

1) Cuando los particulares son prestadores de un servicio público.

2) En los casos en que los particulares ejercen funciones públicas.

3) Cuando los particulares desarrollan actividades que comprometen el interés general.

4) En aquellos casos en los que la protección de otro derecho fundamental haga imperativa la respuesta.

5) Cuando haya estado de indefensión o situación de subordinación frente al particular al que se le eleva la petición.

6) Cuando el legislador autoriza la procedencia de la petición.

La regulación definitiva del derecho de petición ante particulares está contenida en los artículos 32 y 33 de la Ley 1755 de 2015, que recogieron el sistema de reglas construido por la Corte Constitucional. ((Sentencia de Tutela T-487, 2018). Así las cosas la jurisprudencia en esta materia está actualmente más que clara, precisa y contundente frente a su concepto, aplicación, características y cumplimiento.

\section{Análisis de las estadísticas del consultorio jurídico de CECAR en el área de derecho público en relación al derecho de petición durante los años 2016 y 2017}

En nuestro día a día en el Consultorio Jurídico de la Facultad de Derecho de la Corporación Universitaria del Caribe CECAR durante la atención a nuestros usuarios, se realiza en primera medida un registro de llegada de cada usuario, el cual dependiendo de su asunto jurídico es direccionado a una de nuestras oficinas de atención, si el caso corresponde a asuntos de derecho público que no ameriten la designación de estudiantes para que unza como apoderado del usuario, sino que es para consulta, asesoría y realización de documentos a nombre del usuario, es remitido a la monitoria correspondiente de Consultorio Jurídico II - Consultas, ya que esta es el área que se encarga de recibir, registrar y designar si es del caso, el asunto jurídico a realizar por parte de los estudiantes o monitores manifestándole al usuario el documento que se va a elaborar.

La elaboración de documentos como son la petición, la acción de tutela, los recurso, los incidentes se utilizan como primera línea de acción para resolverse los conflictos de los usuarios con diferentes entidades públicas y privadas y que según el caso las temáticas varían unas a otras dependiendo de cada caso en particular de cada usuario, pero que las 
El derecho de petición como factor de descongestión judicial en el municipio de Sincelejo - análisis desde la práctica del Consultorio Jurídico de CECAR...

mas reiterativas durante la atención anual del Consultorio Jurídico a la comunidad suelen ser las peticiones presentadas por la deficiencia prestación del servicio de salud, por cuanto en la mayoría de los casos las EPS independiente del régimen si es contributivo o subsidiado incurren en los siguientes errores: i). Demoran la prestación del servicio, ii). No entregan las medicinas no pos, o si las entregan es a destiempo y no acorde con la receta médica, iii). No realizan los procedimientos médicos, iv). No entregan los viáticos cuando remiten al paciente por fuera del municipio de residencia $v$ ). No reconocen las incapacidades médicas o licencias de maternidad, Vi). No quieren hacer los reembolsos.

También obedecen a las inconformidades con los servicios públicos domiciliarios como lo son el de energía, agua potable, saneamiento básico y gas natural donde la temática corresponde al cobro excesivo del consumo, facturas con cobros muy altos, cobro de consumos dejados de facturar por irregularidades en los contadores, cobros por reconexión, reinstalación y suspensión, así mismo otros temas son las peticiones por los comparendos realizados personalmente o a través de medios electrónicos los que comúnmente les llaman foto multas solicitando la caducidad o la prescripción de los comparendos, la prescripción de la acción de cobro o copia de los expedientes contravencionales, así mismo existen otros que se presentan con menor frecuencia como lo son las presentadas por créditos de ICETEX, impuesto predial, habeas data. Es por lo anterior la relevancia de las prácticas jurídicas de los estudiantes de Consultorio y la incidencia que eso tiene en la descongestión judicial, así como en el de permitir el acceso a la justicia de personas de escasos recursos económicos y personas vulnerables, por lo que relacionamos nuestras estadísticas con los siguientes gráficos. 


\section{PERIODO I}

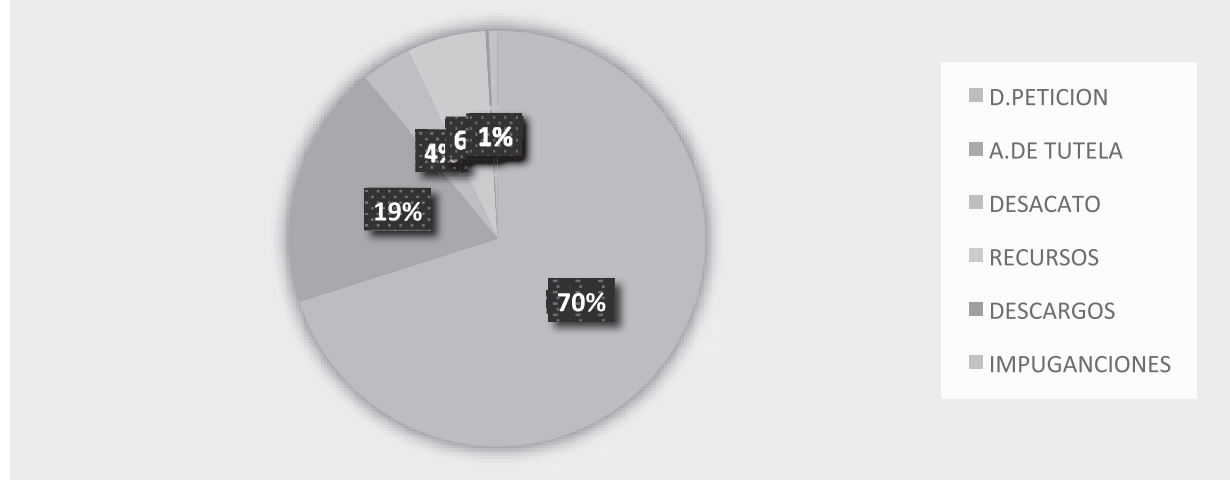

Gráfica 1. Datos estadísticos del Consultorio Jurídico, año 2016

Elaboración propia. Fuente: Datos estadísticos obtenidos de los archivos del

Consultorio Jurídico, del informe final de dirección del año 2016

En la gráfica número 1 se relacionan los documentos elaborados durante el año 2016 en el área de derecho público obteniendo como resultado: 307 derechos de petición equivalente a un 70\%, 83 acciones de tutela equivalentes al 19\%, 17 incidentes de desacatos, equivalentes al 4\%, 27 recursos equivalentes al 6\%, 1 descargo, finalmente se realizaron 3 impugnaciones equivalentes al 3\%. Finalmente de la gráfica número 1 se puede concluir que el documento que con mayor frecuencia se elabora en área de derecho público es el derecho de petición.

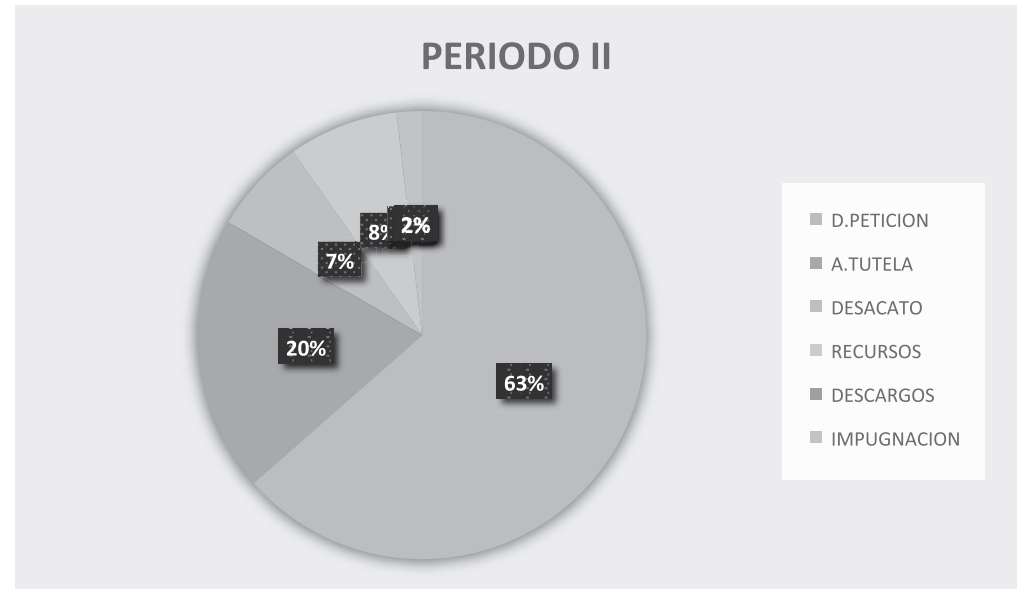

Gráfica 2. Estadísticas de Derecho Público Año 2016- Periodo II.

Elaboración propia. Fuente: Datos estadísticos obtenidos de los archivos del

Consultorio Jurídico, del informe final de dirección del año 2016 
El derecho de petición como factor de descongestión judicial en el municipio de Sincelejo - análisis desde la práctica del Consultorio Jurídico de CECAR...

En el segundo periodo del año 2016 se realizaron 176 derechos de petición equivalentes al 64\%, 55 acciones de tutela equivalentes al \%20, 19 incidentes de desacato equivalentes al 7\%, 22 recursos equivalentes al 8\%, 5 impugnaciones equivalente al 2\%, en el segundo periodo no se realizó ningún descargo. Igualmente en el segundo periodo del año 2016 el derecho petición continúa obteniendo el mayor porcentaje de elaboración de documentos en el área de derecho público.

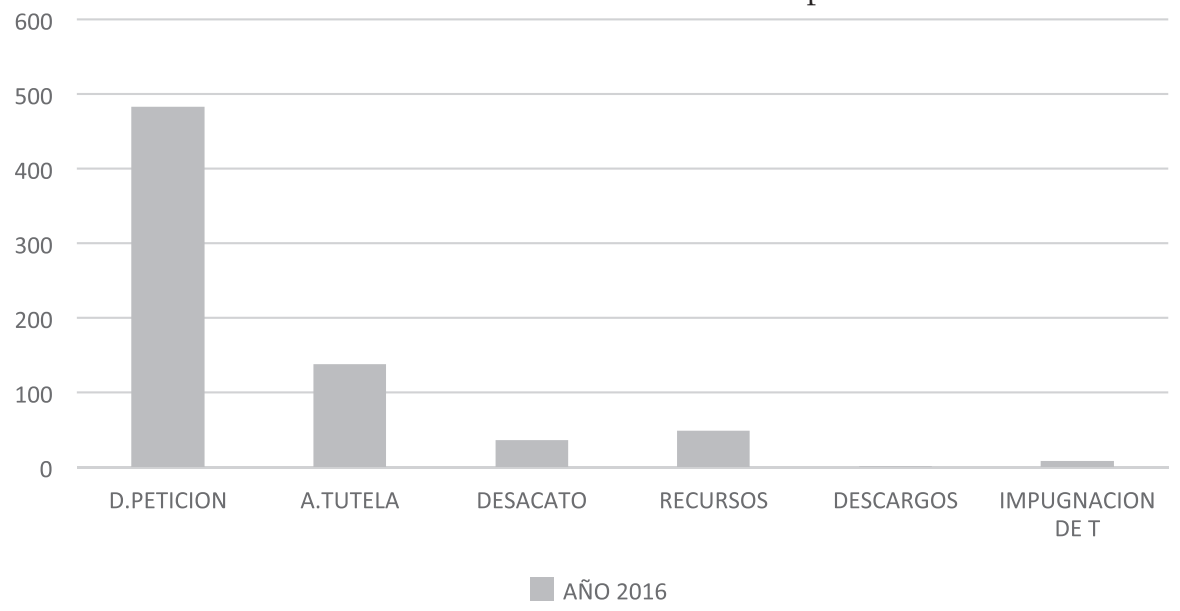

Gráfica 3. Estadística Total del Año 2016 de Derecho Público

Elaboración propia. Fuente: Datos estadísticos obtenidos de los archivos del Consultorio Jurídico, del informe final de dirección del año 2016

\section{TOTAL 2016}
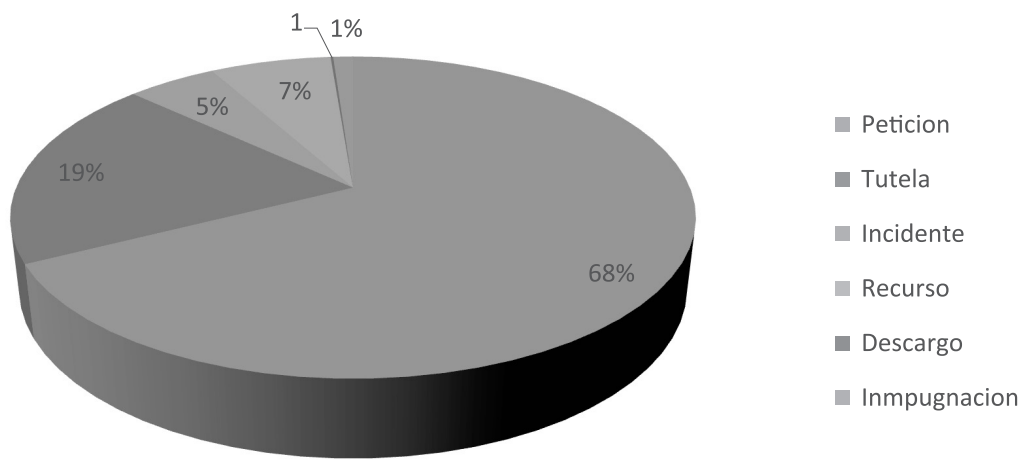

Gráfica 4. Detalle de Trámites 2016

Elaboración propia. Fuente: Datos estadísticos obtenidos de los archivos del

Consultorio Jurídico, del informe final de dirección del año 2016 
Durante el año 2016 en los dos periodos en la dependencia de consultorio jurídico se realizaron un total de 483 derechos de petición equivalente al 68\%, 138 acciones de tutela equivalente al 19\%, 36 incidentes de desacato equivalente al 5\%, 49 recursos equivalente al 7\%, 1 descargo y 8 impugnaciones de tutela equivalente al 1\%. La totalidad de documentos elaborados en el año 2016 deja en evidencia el derecho de petición como el documento con mayor elaboración y los descargos como el documento menos elaborado.

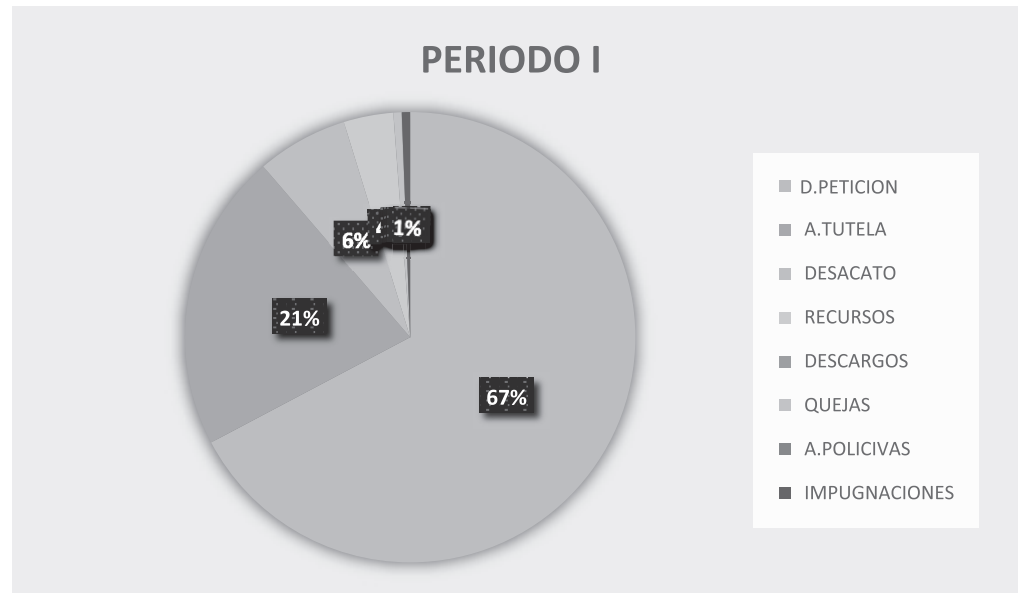

Gráfica 5. Estadísticas de Derecho Público Año 2017-Periodo I

Elaboración Propia. Fuente: Datos estadísticos obtenidos de los archivos del

Consultorio Jurídico, del informe final de dirección del año 2017.

En el periodo primer periodo del año 2017 se realizaron 226 derechos de petición equivalentes al $67 \%, 72$ acciones de tutela equivalentes al $21 \%$, 22 incidentes de desacato equivalentes al 7\%, 12 recursos equivalentes al 4\%, 2 quejas equivalentes al 1\% y finalmente 2 impugnaciones al 1\%. De la gráfica número 4 se puede concluir que se adicionan nuevos documentos como las actuaciones policivas y las quejas a diferencia de los periodos del año 2016 donde estas no fueron realizadas, sin embargo se guarda similitud con el mayor porcentaje en derechos de petición obteniendo este el 67\%. 
El derecho de petición como factor de descongestión judicial en el municipio de Sincelejo - análisis desde la práctica del Consultorio Jurídico de CECAR...

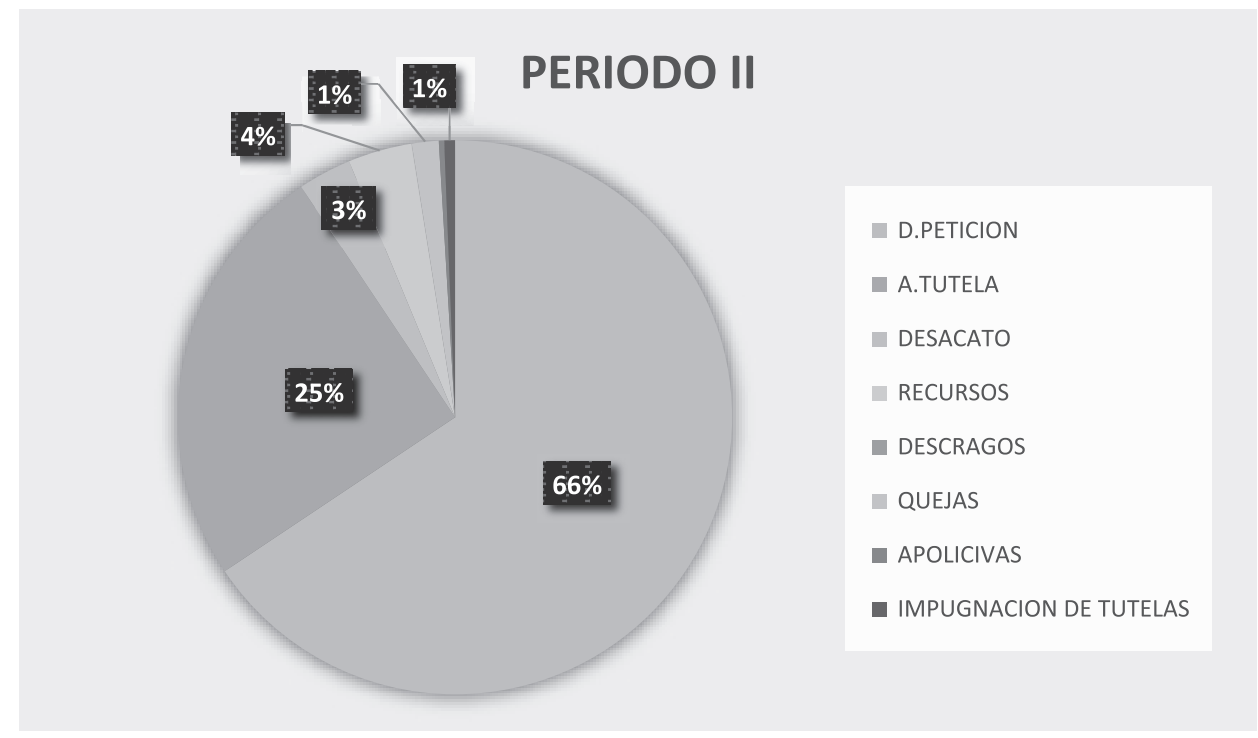

Gráfica 6. Estadísticas de Derecho Público Año 2017-Periodo II

Elaboración Propia. Fuente Datos estadísticos obtenidos de los archivos del

Consultorio Jurídico, del informe final de dirección del año 2017.

En el segundo periodo del año 2017 representado en la Gráfica numero 4 se obtuvieron los siguientes resultados: 210 derechos de petición equivalentes al 66\%,80 acciones de tutela, equivalentes al 25\%, 10 incidentes de desacato equivalentes al 3\%, 12 recursos equivalentes al $4 \%, 5$ quejas equivalentes al 2\%, finalmente se elaboró una impugnación de tutela.

Del anterior gráfico se pudo concluir que al igual que el año 2016 y primer periodo del año 2017, en el segundo periodo 2017 continua siendo el derecho de petición el documento mas elaborado. 
AÑO 2017

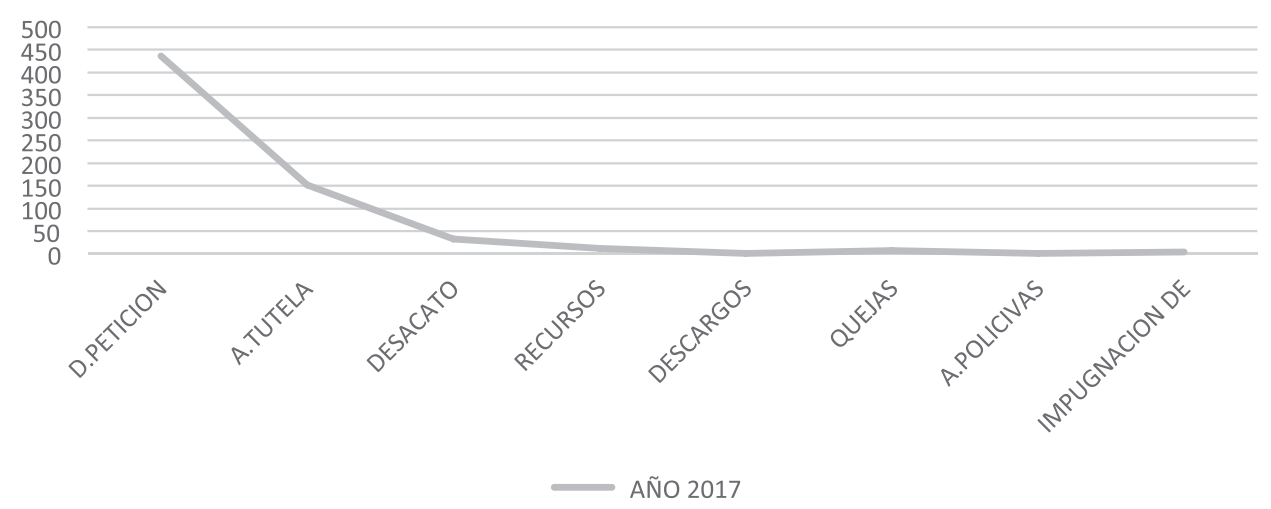

Gráfica 7. Estadística Total del Año 2017 de Derecho Público.

Elaboración Propia. Fuente Datos estadísticos obtenidos de los archivos del

Consultorio Jurídico, del informe final de dirección del año 2017

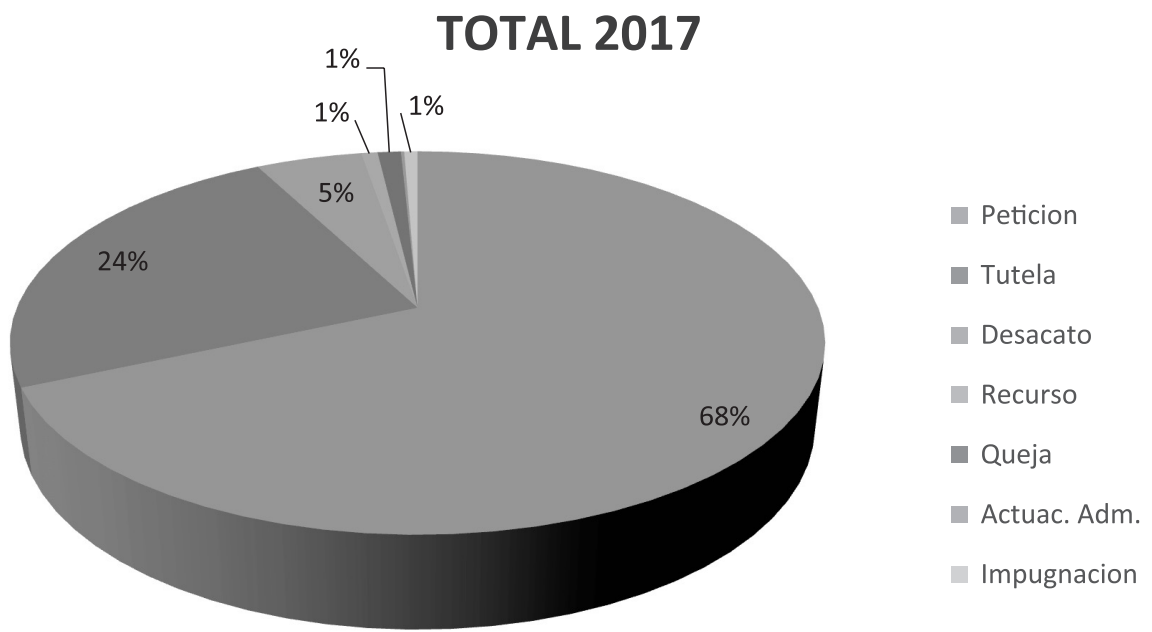

Gráfica 8. Detalle de Tramites 2017

Elaboración Propia. Fuente Datos estadísticos obtenidos de los archivos del

Consultorio Jurídico, del informe final de dirección del año 2017

Finalmente durante el año 2017 en la totalidad de los dos periodos el derecho de petición obtuvo un total de 436 equivalente al 68\%, la acción de tutela 152 equivalente al 24\%, incidente de desacatos 32 equivalente al $5 \%$, recursos 5 equivalente al $1 \%$, quejas 7 equivalente al $1 \%$, actuación policiva 1 y 4 impugnaciones de tutela equivalente al $1 \%$. 
El derecho de petición como factor de descongestión judicial en el municipio de Sincelejo - análisis desde la práctica del Consultorio Jurídico de CECAR...

Del anterior gráfico se puede concluir que el derecho de petición duplica en numero de documentos elaborados a la acción de tutela por lo que es evidente la dimensión tan grande que tiene el ejercicio de este derecho.

\section{ANALISIS ESTADISTICO AREA DERECHO PUBLICO DURANTE LOS AÑOS 2016-2017.}

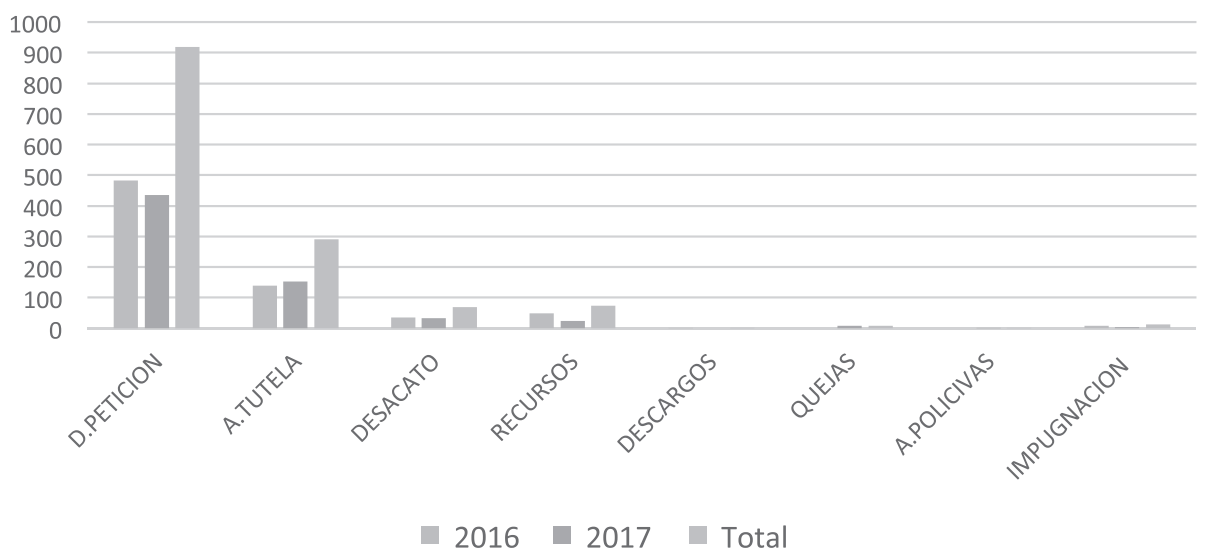

Gráfica 9. Total Años 2016 Y 2017

Elaboración Propia. Fuente Datos estadísticos obtenidos de los archivos del

Consultorio Jurídico, del informe final de dirección del año 2017

\section{TOTAL 2016 Y 2017}

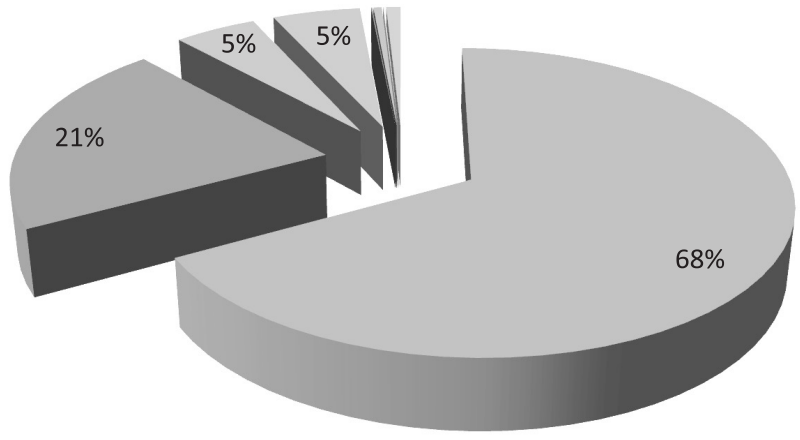

- Peticion

- Tutela

Desacato

necurso

- Descargo

Queja

Actua. Adm.

Impugnacion

Gráfica 10. Total Años por trámites.

Elaboración Propia. Fuente Datos estadísticos obtenidos de los archivos del Consultorio Jurídico, del informe final de dirección de los años 2016 y 2017 
Finalmente durante el acumulado total de los dos años el derecho de petición obtuvo un total de 919 equivalente al 68\%, la acción de tutela 290 equivalente al 21\%, incidente de desacatos 68 equivalente al 5\%, recursos 73 equivalente al 5\%, Descargo 1, quejas 7 , actuación policiva 1 y 12 impugnaciones de tutela.

Para finalizar las estadísticas del gráfico ultimo creado, se concluye inequívocamente la ventaja que del derecho de petición sobre la acción de tutela se triplica y por tanto esta en relación de poco mas de 3 a 1 , por lo que definitivamente el derecho de petición fue el documento mas utilizado durante los dos años que se tratan.

\section{Resultados según muestra}

Para la muestra se tomó el 10\% del total de documentos elaborados durante los años de 2016 y 2017, correspondiendo al derecho de petición el numero de 91 documentos elaborados, para la acción de tutela correspondió el numero de 29 documentos elaborados y para el caso del recurso el numero de 7 documentos elaborados.

\section{RESULTADOS FAVORABLES}

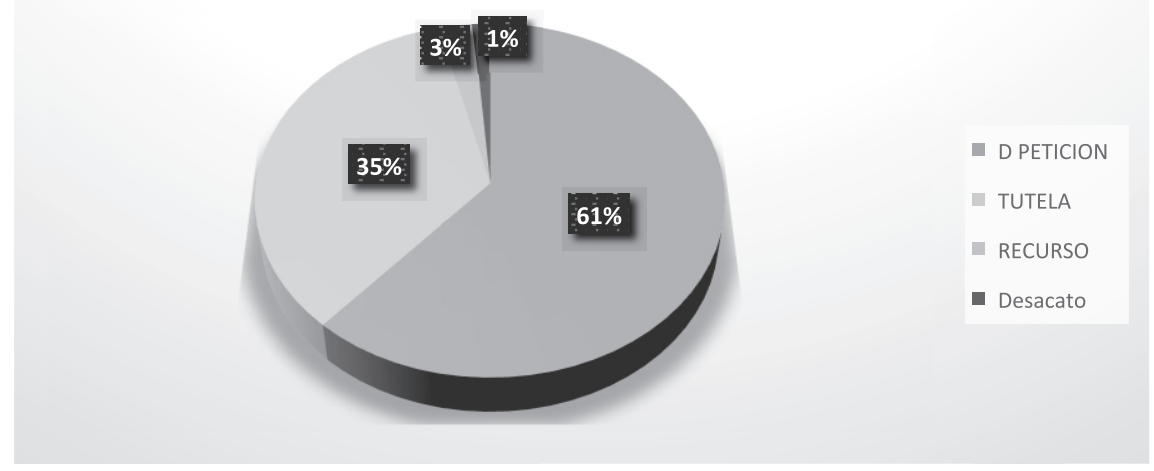

Gráfica 11. Resultados favorables

Elaboración Propia. Fuente Datos estadísticos obtenidos de los archivos del Consultorio Jurídico, del informe final de dirección de los años 2016 y 2017 
El derecho de petición como factor de descongestión judicial en el municipio de Sincelejo - análisis desde la práctica del Consultorio Jurídico de CECAR...

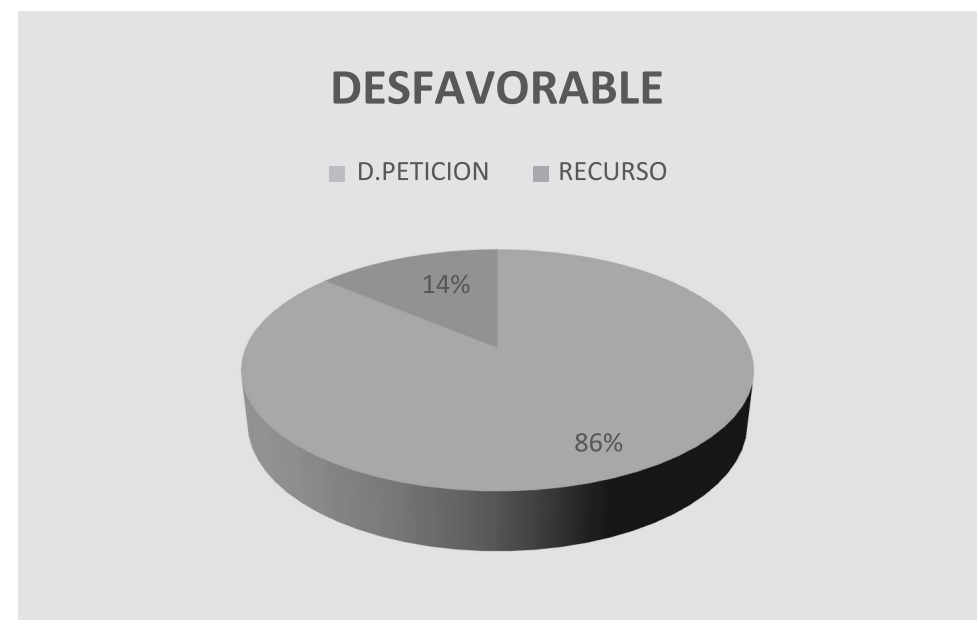

Gráfica 12. Resultados Desfavorables

Elaboración Propia. Fuente Datos estadísticos obtenidos de los archivos del Consultorio Jurídico, del informe final de dirección de los años 2016 y 2017

\section{OTROS}

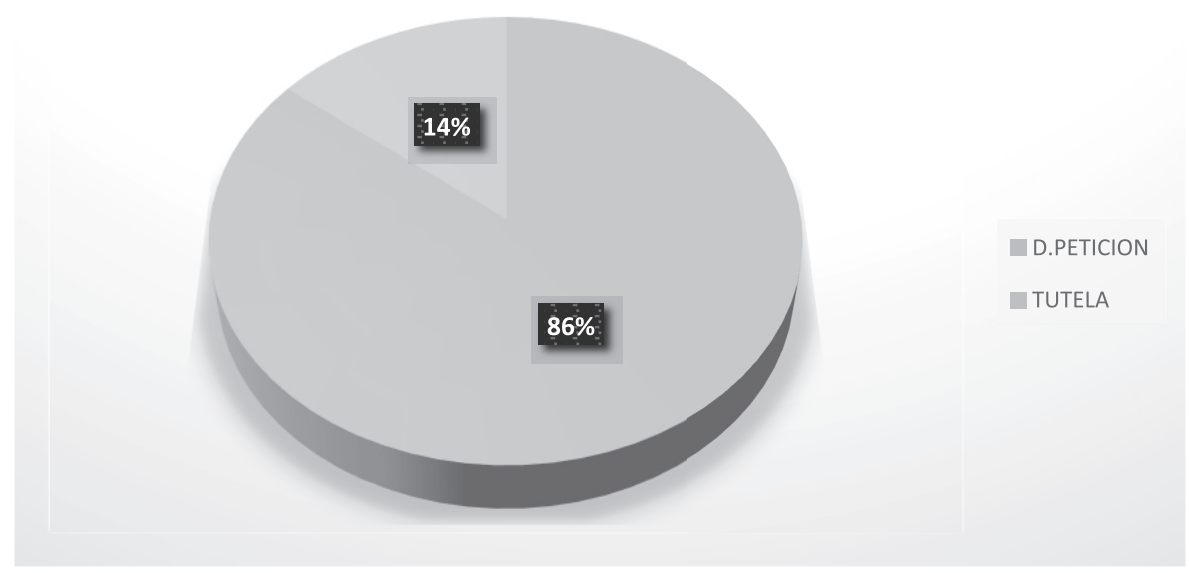

Gráfica 13. Otros

Elaboración Propia. Fuente Datos estadísticos obtenidos de los archivos del Consultorio Jurídico, del informe final de dirección de los años 2016 y 2017

De las anteriores Gráficas descritas se logró discriminar a través de los informes finales de los estudiantes los resultados favorables, los resultados desfavorables y otros resultados como documentos 
sin entregar por el usuario, desistidos y no retirados establecidos en porcentajes de la siguiente manera:

Resultados Favorables: 48 derechos de petición equivalentes al 61\%, 27 acciones de tutela equivalentes al 35\%, 2 recursos equivalentes al 3\% y finalmente 1 desacato equivalente al 1\% para un total de 78 documentos.

Resultados Desfavorables: Tenemos 31 derechos de petición equivalente al $86 \%$ y 5 recursos equivalentes al 14\% para un total de 36 documentos

Otros Resultados: 12 peticiones equivalentes al 86\%, 2 acciones de tutela equivalentes al 14\%, para un total de 14 documentos.

Para un total final de documentos elaborados de que sirvieron de muestra 128 .

Las estadísticas relacionadas demuestran sin lugar a duda alguna que el derecho de petición no solo es un derecho fundamental o un mecanismo de participación ciudadana, sino que también es la herramienta primaria para acceder a la justicia y reclamar derechos individuales o colectivos, pues los que han sido favorables han impactado a la comunidad de Sincelejo y han evitado que futuros procesos lleguen a instancias de conciliaciones prejudicial, demandas judiciales y sobre todo han evitado que el conflicto suscitado congestione los anaqueles de los despachos de los jueces, de las entidades públicas, así como de las privadas, pues con la solución dada con la sola presentación de la petición, debidamente argumentado y soportado han dado a esta herramienta la posible denominación de ser un verdadero mecanismo de solución de conflicto y lo mejor a un, sin intervención de terceros que tengan que avalar algún acuerdo.

Si el derecho a pedir no hubiese sido instituido en nuestro ordenamiento jurídico Colombiano bajo los parámetros en los que está establecido hoy más que nunca estuviéramos inmersos en una congestión judicial anárquica, debido que cualquier simple problema por muy pequeño que sea tendría que derivar al final en un pleito judicial o en una conciliación prejudicial como mínimo, lo que elevaría grandemente la ya recargada y apurada rama judicial en sus distintos órdenes jerárquicos, pues es así como un simple comparendo prescrito derivaría en un proceso de nulidad y restablecimiento del derecho, el del pago de un seguro de vida en una demanda civil contractual, los servicios de salud insatisfechos en tutelas, incidentes y hasta en demandas laborales, es por ello que los porcentajes favorables hablan por sí solos y 
demuestran ampliamente la efectividad y eficiencia en la descongestión judicial del municipio de Sincelejo para los años de 2016 y 2017.

El derecho de petición durante las prácticas intramurales de la asignatura del Consultorio Jurídico de CECAR durante varios años ha sido el medio más utilizado por usuarios para acceder a la justicia y con ello al reconocimiento de los derechos reclamados por medio de este derecho fundamental, mecanismo de participación ciudadana y porque no mecanismo de solución de conflicto, pues en el área de derecho público que es donde pertenece la petición, la diferencia entre esta herramienta y los otros medios utilizados es bastante amplia, pues la tutela que es el segundo medio que se utiliza para acceder a la justicia es ampliamente superada por la petición como se evidencia en las gráficas anteriormente descritas, lo que deslumbra de cómo la gente del común y de escasos recursos económicos según su caso, demanda mayor documento a realizar a la petición lo que convierte a este derecho fundamental en una herramienta idónea para exigir sus derechos y manifestar sus inconformidades, accediendo con ello a la justicia y contribuyendo a las descongestión judicial en la ciudad de Sincelejo.

\section{Efectividad del derecho de petición desde la práctica jurídica del consultorio jurídico de CECAR en la descongestión de los despachos judiciales}

De acuerdo al Tribunal Contencioso Administrativo del Cauca: "La efectividad del derecho de petición radica en que lo resuelto trascienda el ámbito del sujeto que lo adopta, que se conteste en forma total a sus peticiones y sea puesto en conocimiento del peticionario." La Petición vista desde tres puntos de vista desde deslumbra su importancia y trascendencia en nuestro ámbito jurídico, social, económico y político, ya que es una herramienta que empodera a los ciudadanos y los dota de capacidades para nivelarse a las autoridades otorgándoles confianza y seguridad para exigir de las autoridades respuestas veraces oportunas y coherentes con lo solicitado, esos punto de vista son: como Derecho fundamental, Mecanismo de Participación ciudadana y como Mecanismo Alternativo de Solución de Conflicto.

Desde estos puntos de vista el Consultorio Jurídico del Programa de Derecho de la Corporación Universitaria del Caribe apunta a lograr el máximo grado de efectividad. Teniendo como efectividad la conjunción entre eficiencia y eficacia para el cumplimiento de los fines de la petición. 
1. La Petición Como Derecho Fundamental: Desde Consultorio Jurídico del Programa de Derecho de la Corporación Universitaria del Caribe se contribuye a garantizar este derecho constitucional el cual es inherente a la persona humana, dicha contribución consiste en la atención, asesoría, elaboración y presentación de documentos, esto lleva a la dignificación de nuestros usuarios y su entorno familiar con lo cual se le permite acceder a la justicia al usuario mediante la petición como primer contacto con la entidad con la cual tiene la inconformidad y de la cual se está exigiendo algo.

2. La Petición Como Mecanismo de Participación Ciudadana: El Consultorio Jurídico del Programa de Derecho de la Corporación Universitaria del Caribe evidencia su contribución en este campo por medio de la atención, asesoría, elaboración y presentación de documentos que permiten que el ciudadano del común por medio de sus solicitudes participen en la construcción y desarrollo de herramientas para mejorar su entorno social y a la vez les permite pedir a las autoridades explicación por sus actuaciones, de esta manera se consigue fortalecer nuestra democracia.

3. La Petición Como Herramienta de Solución de Conflicto: La participación del Consultorio Jurídico del Programa de Derecho de la Corporación Universitaria del Caribe se muestra en el sentido que los usuarios al solicitar nuestros servicios por regla general presentan una insatisfacción en el uso o prestación de los servicios públicos lo que generaría un conflicto, en este campo se contribuye con la atención, asesoría, elaboración y presentación de documentos argumentados jurídicamente y basados en su viabilidad legal su respuesta satisface y soluciona la problemática presentada.

Por lo anterior consideramos que desde estos puntos de vista se garantizan los postulados y fines esenciales de un Estado Social Derecho desde la efectividad del Derecho de Petición. Lo cual se demuestra con los datos estadísticos que se relacionaron a este capítulo de los años 2016 y 2017 donde se evidencia la efectividad e incidencia que desde el consultorio se está generando para la descongestión judicial y para tener acceso a la justicia, pues al realizar las diferentes peticiones para los múltiples casos que se tramitan a los usuarios que ante nosotros acuden. 
El derecho de petición como factor de descongestión judicial en el municipio de Sincelejo - análisis desde la práctica del Consultorio Jurídico de CECAR...

\section{Conclusiones}

La petición es un gran logro del Estado Social de Derecho porque empodera a las personas dotándolas de herramientas para poder exigir a las autoridades soluciones concretas y factibles a sus necesidades, desde Consultorio Jurídico De La Corporación Universitaria del Caribe CECAR, se ha venido fortaleciendo ese postulado de la "Dignidad Humana" y garantizando ese derecho fundamental por medio de los servicios que presta a la comunidad y capacitando, sensibilizando y dotando a futuros profesionales para prestar un servicio de calidad. La proyección social que se denota y el impacto que logra la gestión del Consultorio Jurídico es establecida de la siguiente forma:

En primer lugar podemos concluir que es clara e inequívoca la incidencia del derecho de petición en la descongestión judicial en el municipio de Sincelejo durante los años 2016 y 2017 desde la práctica de consultorio jurídico de CECAR, pues mediante la elaboración de sendos documentos realizados a los usuarios por nuestros personal estudiante, monitor y con revisión del docente asesor como lo son las peticiones, tutelas, recursos, incidentes de desacatos, descargos e impugnaciones, se ha logrado incidir positivamente en muchos asuntos en los cuales de no haber sido por el derecho de petición presentado, muy probablemente hubiesen proseguido por parte del usuaria a su solución por medio de procesos judiciales como los de nulidad y restablecimiento del derecho, la acción de tutela, la acciones de protección al consumidor, demanda por incumplimiento de contrato de seguros entre otras.

Así mismo se estableció que el derecho de petición en nuestro país desde sus inicios como estados independientes de la corona española hasta nuestros días como República soberana, ha evolucionado positivamente en nuestro ordenamiento jurídico, pues se ha instituido constitucionalmente el derecho de petición como derecho fundamental de todas las personas, así como mecanismos de participación ciudadana dándole con ello pluralidad de funciones, soportada en la ley que regula en detalle sus características, concepto, requisitos, clases entre otras cosas, sumado a que todos los preceptos se encuentran ratificados ampliamente y sin lugar a inexactitudes por la jurisprudencia del país decantando de forma, clara, precisa y sin restricción alguna la especial protección que este derecho demanda.

Cómo segundo punto se analizó las estadísticas del Consultorio Jurídico en derecho público y respecto de la petición y se concluyó que en la práctica del consultorio jurídico de CECAR de los años 2016 y 2017 
quedo claro que el derecho de petición es el medio más utilizado para acudir de manera directa a la reclamación de los derechos del usuario o a la solución del problema planteado con un $68 \%$ frente a su segundo competidor que fue la acción de tutela con un $21 \%$.

La tercera y última conclusión nos lleva a establecer sin miedo alguno la efectividad del derecho de petición desde los diferentes puntos de vista tomados (como derecho fundamental, como mecanismo de participación o como herramienta de solución de conflicto), pues de los 1371 casos registrados en los años de 2016 y 2017 en materia de derecho público, el más utilizado para reclamar los derechos fue precisamente el derecho de petición quien con un $68 \%$ de utilización correspondiente a 919 peticiones presentadas con lo que se demuestra el amplio margen de diferencia frente a la acción de tutela que con un 21\% correspondiente a 290 documentos elaborados, por lo que se ubica en segundo lugar de utilización para acceder a la justicia y reclamar sus derechos, es por ello que podemos concluir que desde la práctica del Consultorio Jurídico de CECAR se impactó directamente en la comunidad para que tuvieran acceso a la justicia y a su vez coadyuvo a la descongestión de los despachos judiciales del municipio de Sincelejo, puesto que del total de los documentos elaborados durante los dos años relacionados en las estadísticas, se demostró con el muestreo del 10\% correspondiente al número de 128 documentos, se estableció que 78 fueron resueltos de manera favorable, correspondiendo al derecho de petición el $61 \%$ frente a un 35\% de la acción de tutela, seguido por el 3\% del recurso.

\section{Referencias}

(s.f.). Obtenido de http://app.vlex.com.ezproxy.cecar.edu.co:8080/\#CO/ search/jurisdiction:CO+content_type:1/derecho+de+peticion/CO/ vid/571260906/graphical_version

(Sentencia de Tutela T-487, Magistrado Ponente: Alberto Rojas Rios (Corte Constitucional colombiana 28 de julio de 2018).

Bartomeu, P. (1997). El Derecho de Petición. Madrid: Marcial Pons.

Constitución, 1821 (Comgreso De La República 30 de qgosto de 1821). Obtenido de http://www.cervantesvirtual.com/obra-visor/colombia-16/html/0260ce5e-82b2-11df-acc7-002185ce6064_1.html

Constitución Politíca de Colombia (1991). 
El derecho de petición como factor de descongestión judicial en el municipio de Sincelejo - análisis desde la práctica del Consultorio Jurídico de CECAR...

Constitución Politica de la República de Colombia (1886). Obtenido de http://americo.usal.es/oir/legislatina/normasyreglamentos/constituciones/colombial886.pdf

Constitución Política de los Estado Unidos de Colombia (Congreso De la REpública 08 de mayo de 1863).

Ley 1437, Código de Procedimiento Administrativo y de lo Contencioso Administrativo (Congreso De La Republica 18 de enero de 2011).

Ley 1755 (30 de junio de 2015). Obtenido de http://www.secretariasenado. gov.co/senado/basedoc/ley_1755_2015.html

Penagos, Gustavo. "La Vía Gubernativa" Ediciones Doctrina Y Ley Ltda

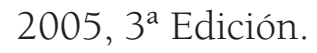

Rodríguez R., Libardo. "Derecho Administrativo General Y Colombiano". Editorial Temis S.A., 18ª Edición 2013.

Sentencia T-332, Magistrado Ponente Alberto Rojas Rios (Corte Constitucional colombiana 01 de junio de 2015). 